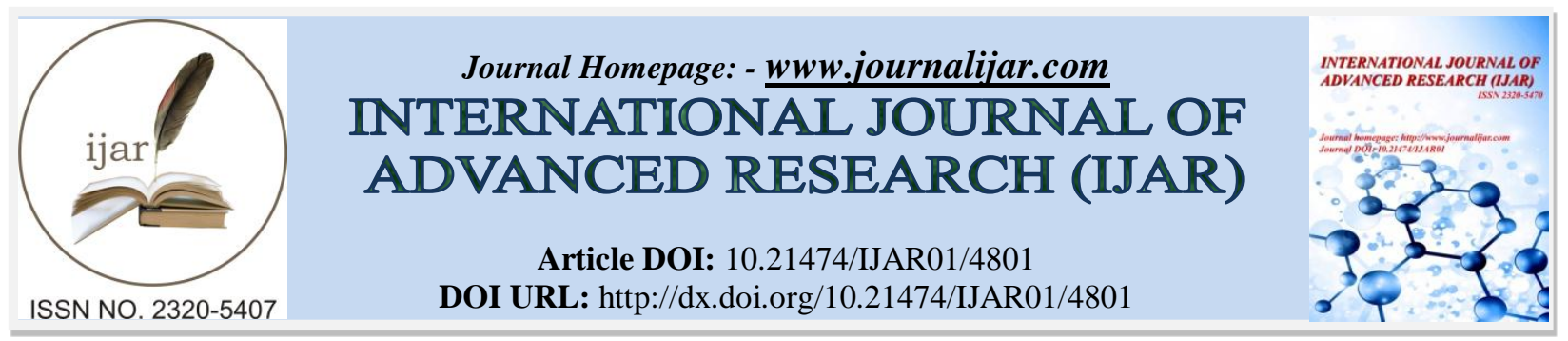

RESEARCH ARTICLE

\title{
A PILOT STUDY OF KARBAKANDHI ENNAI FOR THE TREATMENT OF PCOS (SINAIPAI NEERKATTI).
}

S. Keerthana.

Department of Kuzhandhai Maruthuvam, National Institute of Siddha, Chennai-600047, Tamil Nadu, India.

Manuscript Info

..........................

Manuscript History

Received: 10 May 2017

Final Accepted: 12 June 2017

Published: July 2017

Key words:-

Sinaipai Neerkatti, PCOS, Karbakandhi Ennai

\section{Abstract}

The active role of siddha medicine in combating diseases is being widely recognized nowadays. In that way I have a taken a condition called PCOS which in Tamil commonly known as Sinaipai Neerkatti and Karbakandhi Ennai is the drug that I have taken for the study from the literature Anubhava Siddha Vaidhya Muraigal which has been indicated for infertility. In this pilot study 10 patients were recruited from NIS, Sool Magalir Maruthuvam OPD for the study and given the treatment for three menstrual cycles along with some food restrictions and lifestyle modifications.

Copy Right, IJAR, 2017,. All rights reserved.

\section{Introduction:-}

The majority of PCOS women have irregular periods with menstruation being very erratic, infrequent, or painful, with an increase in flow and cramping. Chronic anovulation may present as oligomenorrhea, amenorrhea, dysfunctional uterine bleeding, and/or infertility. Reproductive system symptoms may include anovulation and miscarriages, among other things. PCOS is the most common cause of infertility. Seventy five percent of anovulatory infertility is due to PCOS, and that PCOS women have a thirty to fifty percent first trimester miscarriage rate. Sixty to eighty percent of PCOS women do have weight problems (obesity) because of the metabolic abnormalities seen with the disease. Insulin resistance and metabolic syndrome may be seen in conjunction with high waist circumference, high Body Mass Index (BMI), and abnormal SHBG. Insulin resistance has also been known to cause Acanthosis Nigricans which are brown or black velvety patches of skin that appear hyperpigmented and are usually seen on the necks, thighs, and armpits of PCOS patients who have insulin resistance

Recently two studies have found linkage between a marker (D19S884 at chromosome 19) ${ }^{[1]}$ located near the insulin receptor gene and PCOS. Although the putative PCOS gene in this region remain to be identified, likely involvement in signal transduction mechanisms, leading to altered expression of a family of genes involved in steroidogenesis and /or insulin action.

Metformin, an insulin sensitizer, seems to decrease serum insulin concentrations in women with PCOS, thus directly counteracting these effects of insulin and controlling the abnormal biochemical profile commonly found in PCOS

\section{Current modern treatment of PCOS:-}

The treatment of PCOS consists mainly of controlling the symptoms of the syndrome in an attempt to achieve shortand long-term goals. Short-term goals include regulation of menses, treatment for infertility if required, control of hirsutism and acne, and stabilization or reduction of weight. Long-term goals include the prevention of endometrial hyperplasia and diabetes, avoiding obesity and the control of biochemical risk factors associated with heart disease. 
Multiple concomitant therapies are often necessary in order to address the variety of symptoms exhibited in PCOS, but they may also confer additive benefits with regards to the efficacy of treatment.

The combined oral contraceptive pill (COCP) effectively controls many symptoms of PCOS. In addition to regulating menstrual cycles, endometrial hyperplasia is prevented and the incidence of acne and hirsutism is reduced, presumably because COCP suppresses pituitary gonadotrophin production by negative feed-back mechanism, thus decreasing ovarian steroidogenesis.

In anovulatory women with PCOS, the first-line treatment to improve fertility is the administration of clomiphene citrate, an antagonist of E2 followed by chronic low-dose FSH, if the former alone is unsuccessful. GnRH agonists such Bursereline acetate, are also used for ovulation induction in patients with high tonic LH levels, to improve pregnancy and decrease miscarriage rates ${ }^{[2]}$.

Laparoscopic ovarian drilling is also used in normal-weight patients with high LH tonic concentrations, since it decreases ovarian androgen production and improves ovulation rates.

\section{Objectives Of The Study:-}

\section{Primary:-}

- To evaluate the clinical efficacy of Karbakandhi Ennai for PCOS.

\section{Secondary:-}

- To study the effect of other associated factors like Age, Life style, Habits.

- To study the impact of the drugs on hormones secreted in women.

\section{Material and Methods:-}

\section{Ingredients:-}

$\begin{array}{ll}\text { Kandhagam (Purified Sulphur) } & -20 \mathrm{~g} \\ \text { Poondu (Garlic) } & -100 \mathrm{~g} \\ \text { Gingelly oil (Sesame oil) } & -1 \text { litre }\end{array}$

\section{Preparation:-}

Powder the purified kandhagam and grind with poondu. Paste the mixture at the base of the utensil, after it is dried add gingelly oil and heat it till the oil turns to pink color.

Dosage: 5-10 drops with half-baked egg yolk

Duration: 3 Months.

\section{Administration of the Drug:-}

The drug will be administered initially for 20 days and then breaking point of 10 days will be given, thereupon the drug will be administered for next 20 days. Likewise the administration will follow for three months until regularization of menstrual cycle occurs.

\section{Clinical Studies:-}

An open clinical trial done at Ayothidoss Pandithar Hospital, National Institute of Siddha, Tambaram sanatorium, Chennai-47. Patients having polycystic ovary on ultrasound along with Patients reporting with Irregular menstrual cycle were enrolled for the study after careful screening from Sool Magalir Maruthuvam OPD, at Ayothidoss Pandithar Hospital of National Institute of Siddha. Before initializing the study, the trial drug which is mentioned in Siddha literature for the management of infertility in women was selected and the study is conducted, after the proposal was screened by the Screening committee of National Institute of Siddha. The trial was also approved by the Institutional Ethics Committee (IEC), approval number of Karbagandhi Ennai for the treatment of Sinaipai Neerkatti with IEC is approval number 24-12-2013, NIS/IEC/7/2013-14-25. The trial was registered in Clinical trial registry of India with the registration number CTRI/2014/06/004709.

\section{Conduct of the study:-}

The trial drug was prepared by me after getting proper authentication of raw drugs from the Medicinal botany department at NIS, Chennai 47, and Chemistry department in Siddha central Research Institute, Arumbakkam, Chennai 106. The trial drug was prepared by the standard operating procedure as mentioned in the protocol. 
The patients were recruited for the trial based on inclusion and exclusion criteria and after getting the consent from the patient. 10 patients were included in this study. All the patients were recruited from OPD of Sool Magalir Maruthuvam and separate proforma was maintained for every patient. The patients were given the trial drug alone for the study period and followed up once in 10 days. After completion of the course of the trial drug Ultrasonagram was done and thereafter followed for another period of one month.

\section{Results and Discussion:-}

The results observed during the study period were discussed by the author below.

Among the 10 patients included,

In Age group among the 10 patients $70 \%$ (7 patients) were in the age group of 20-24, 20\% (2 patients) in $25-29$, and $10 \%$ (1 patient) in 30-35 age.

\begin{tabular}{|c|c|c|}
\hline Age Group & Number of Patients & Percentage \\
\hline $20-24$ & 7 & 20 \\
\hline $25-29$ & 2 & 10 \\
\hline $30-35$ & 1 & 20 \\
\hline
\end{tabular}

In Diet all 10 patients were non vegetarian.

Regarding Family history among the 10 patients $60 \%$ (6 patients) had positive family history of PCOS and $40 \%$ (4 patients) had negative history.

\begin{tabular}{|c|c|c|}
\hline Family History & & Percentage \\
\hline 6 & Positive & 60 \\
\hline 4 & Negative & 40 \\
\hline
\end{tabular}

In Lifestyle, $100 \%$ of them had sedentary lifestyle based on the nature of their work.

In USG PCOS, all the 10 patients had bilateral PCOS complaints in the ultrasonagram of the pelvis.

According to Menarche among the 10 patients, 50\% (5 patients) attained menarche by the age between $11-13,30 \%$ (3 patients) by the age between 14-16, and 20\% (2 patients) by the age between $8-10$.

\begin{tabular}{|c|c|c|}
\hline Age Group & Number of Patients & Percentage \\
\hline $11-13$ & 5 & 50 \\
\hline $14-16$ & 3 & 30 \\
\hline $8-10$ & 2 & 20 \\
\hline
\end{tabular}

With respect to duration of menstrual cycle among the 10 patients, $30 \%$ (3 patients) had cycle less than 40 days, 40\% (4 patients) had cycles between 40-80 days, and 30\% (3 patients) had cycle above 90 days.

\begin{tabular}{|c|c|c|}
\hline Duration of Menstrual Cycle & Number of Patients & Percentage \\
\hline Less than 40 days & 3 & 40 \\
\hline Between 40-80 days & 4 & 30 \\
\hline Above 90 days & 3 & 30 \\
\hline
\end{tabular}

After treatment Out of 10 cases only 30\% (3 patients) had persistent amenorrhoea with the duration of menstrual cycle above 90 days, $60 \%$ (6 patients) had corrected menstrual cycle with the duration of menstrual cycle between 30-40 days, and $10 \%$ (1 patient) had dysfunctional uterine bleeding.

\begin{tabular}{|c|c|c|}
\hline Duration of Menstrual Cycle & Number of Patients & Percentage \\
\hline Between 30-40 days & 6 & 10 \\
\hline Dysfunctional Uterine Bleeding & 1 & 30 \\
\hline Above 90 days & 3 & \\
\hline
\end{tabular}

Laboratory investigation of blood and urine were done for all 10 cases which were all within normal range, the hormonal analysis were also normal, and the ultrasound showed PCOS changes in the ovaries before treatment. 
After the completion of the trial the ultrasound was repeated which showed persistent PCOS changes but the volume of the ovaries considerably decreased to some extent with respect to previous scan of the corresponding patients.

Inference from the data collected from the study depicts the predominance of PCOS is higher in the sedentary workgroup, with positive family history, and the diet since all the 10 patients recruited for the study came under non-vegetarian and junk food eater.

\section{Conclusion:-}

After treatment Out of 10 patients, 30\% of the patient had no improvement with persistent irregular menstrual cycle, $10 \%$ had dysfunctional uterine bleeding, and the remaining $60 \%$ of the patients had regular menstrual cycles but not consistent during the follow up period of three months.

Though the study was started to ensure the therapeutic efficacy of the drug in treating Sinaipai Neerkatti (PCOS) patients the purpose did not resolve since the ultrasound after treatment showed persistent of PCOS, but among the 10 patients $60 \%$ of them had correction of menstrual irregularity problem and also the drug helped in reducing the BMI level by $40 \%$ altogether. Moreover there were no adverse effects observed in the clinical trial of the herbomineral drug Karpagandhi Ennai. Hence further studies like increasing the dose of the drug and duration of follow up of the patients can be taken up to establish the efficacy of the drug even more accurately.

\section{Bibiliography:-}

1. Urbanek, M. The genetics of the polycystic ovary syndrome. Nat. Clin. Pract. Endocrinol. Metab 3, 103-111 (2007).

2. Balen, A. H., Tan, S. L., MacDougall, J. \& Jacobs, H. S. Miscarriage rates following in-vitro fertilization are increased in women with polycystic ovaries and reduced by pituitary desensitization with buserelin. Hum. Reprod. 8, 959-964(1993).

3. Anubhava Siddha Vaidhya Muraigal, $3^{\text {rd }}$ edition 1989, author Balaraamaiyaa- Pg 80-81

4. Gunapaadam Thathu Seeva Vaguppu

5. B.D Chaurasia - Textbook of Anatomy

6. Sembulingam - Textbook of Physiology

7. D.C Dutta -Textbook of Gynaecology

8. Robert W Shaw -Gynaecology Fourth Edition 